other spending options. It is easier to make a case for additional spending on health care if the existing programme concentrates on interventions that are clearly high priorities and additional interventions that offer significant benefits can be identified. The case for higher levels of funding will have to be made on the basis of a demonstration of the cost effectiveness of additional spending.

International comparisons of spending are sometimes misleading as they take no account of differences in the cost of providing services and the efficiency of provision. However, comparisons show that the United Kingdom spends less than the average for other developed industrialised countries, and has held the proportion of gross domestic product spent on health nearly constant over 10 years. There is evidence from opinion polls that the public are in favour of higher spending. Experience in other countries suggests that it is possible to remain prosperous at the same time as devoting a larger share of gross domestic product to health care.

If increases in overall health care expenditure are to be justified on grounds of cost effectiveness many developments will be in continuing care and in the expansion of established treatments for conditions that are not life threatening. ${ }^{+}$The effects of the aging of the population are mainly to increase needs in these areas. It also will not be easy to justify additional funding for those parts of the country that are already relatively well funded until a more equal distribution is achieved.

There is no reason to believe that the present mix of spending on prevention, health promotion, primary care, secondary care, and tertiary care reflects the pattern of cost effective available interventions. Too little data exist to allow these comparisons to be made. Again the principle should be to choose the funding of each level of care to achieve the maximum effect with any level of spending, but it is not currently possible to do this.

I have suggested above that the debate about the level of funding will in future be conducted on the basis of identifying additional, cost effective interventions that have a higher priority than other spending in the public and private sectors. As needs for care grow, with the additional opportunities provided by advances in medicine and the aging population, many opportunities will probably exist for identifying high priorities for spending within health and personal social services. ${ }^{10}$ Higher spending on health and social care is likely to be acceptable to the public but will bring with it a greater need to demonstrate the effectiveness and cost effectiveness of interventions.

1 BMA. Leading for health. A BMA agenda for health. London: BMA, 1991 2 Sheiber G, Poullier J-P, Greenwald L. Health care systems in twenty four countries. Health Affairs 1991;10:22-38.

Robinson R. Health expenditure: recent trends and prospects for the 1990 s. Public Money and Management 1991;11:19-29.

4 Normand C. Economics, health, and the 2029 . $1572-7$

5 Cichon M. Health sector reforms in central and eastern Europe. International Labour Review 1991:130:3.

6 Figueras J, Normand C, Roberts J, McKee M, Hunter D, Karokis A, et al. Health care infrastructure needs of the lagging regions. Report to the Commission of the European Communities. London: London School of Hygiene and Tropical Medicine, 1991

7 Phelps C, Newhouse J. Co-insurance and the demand for health care. Santa Monica: Rand Corporation, 1974

8 McGuire A, Henderson J, Mooney G. The economics of health care. London: Routledge and Kegan Paul, 1988

9 Proper C, Maynard A. Whither the private health care sector. In: Culver A, Maynard A, Posnet J, eds. Competition in health care-reforming the NHS. London: Macmillan, 1990

10 Bosanquet N, Gray AM. Will you still love me? New opportunities for health services for elderly people in the 1990 s and heyomd. Birmingham: Natior Association of Hospitals and Trusts, 1989

\title{
Agenda for health: an economic view
}

\author{
Cam Donaldson
}

Leading for Health: a BMA Agenda for Health poses some searching questions on funding of health care: "How much should be spent on the health and community care services? How can that amount be determined?"' Unfortunately, the suggested approach to analysing these questions is flawed. In this article I explain why this is the case and what the role of economics should be in setting an agenda for health, in particular in setting the health care budget.

\section{How not to set an agenda: international comparisons}

Often, much is made of data on mortality, morbidity, and health care expenditure across countries (usually those in the Organisation for Economic Co-operation and Development (OECD)). An "international comparisons industry" has become established, using such data not because it tells us what we want to know but rather because it's there. The BMA's agenda falls into the same trap. On the one hand the document claims that there is no " "right' amount to spend on the NHS." On the other hand it contains several international comparisons, implying that there is a magic number (of pounds spent on health care) to which all societies should be moving: "If Britain were to bring its expenditure up to the average for OECD countries then about another six billion pounds would be needed for the health service this year."

One problem with such comparisons is that health care is defined differently in different countries. It is well known that one of the reasons why Sweden seems to spend more than the United Kingdom is that Sweden has one of the highest rates of placing elderly people in institutions. Expenditure on these institutions is included in Sweden's total expenditure on health care. So like is not being compared with like.

Even if expenditure was defined similarly across countries, international comparisons would still be $\mathrm{S}$ flawed. From the 21 OECD countries for which a comparison can be made (table) take Australia, for o instance. ${ }^{2}$ Some countries spend less than Australia and achieve better health outcomes (for example, Denmark and Japan); other countries spend more but . do not necessarily do better on outcomes (for example, $\tilde{\omega}$ the United States and France). Can anything be inferred about the allocation or misallocation of health 0 care resources in Australia? Unfortunately not. The mortality data are crude indicators of health. They are ? not measures of the potential product of health care. Health care is productive only if it improves mortality or morbidity or prevents deterioration.

The use of international comparisons is naive. Not $\stackrel{\mathbb{D}}{\stackrel{2}{2}}$ surprisingly, when based on such methods, a judgment of the effective impact of health care is elusive. It 8 always will be, no matter how good the data are in the future. It is the method that is at fault. We need methods which tell us, within a country, what are the costs and benefits of changing the current uses of health care resources and of expanding or contracting the health care budget relative to other health producing activities. 
Health care expenditure per capita, male life expectancy, and perinatal mortality in OECD countries *

\begin{tabular}{|c|c|c|c|}
\hline & $\begin{array}{c}\text { Per capita } \\
\text { expenditure } \\
(1982)(\$) \dagger\end{array}$ & $\begin{array}{c}\text { Male life } \\
\text { expectancy at age } \\
40 \text { (1980) (years) }\end{array}$ & $\begin{array}{c}\text { Perinatal } \\
\text { mortality }(1981)\end{array}$ \\
\hline Australia & 798 & 33.9 & $1 \cdot 30$ \\
\hline Austria & 684 & $32 \cdot 5$ & $1 \cdot 20$ \\
\hline Belgium & 636 & $32 \cdot 0$ & $1 \cdot 30$ \\
\hline Canada & 1058 & $34 \cdot 0$ & 1.07 \\
\hline Denmark & 736 & 33.9 & $0 \cdot 90$ \\
\hline Finland & 629 & 31.8 & 0.79 \\
\hline France & 996 & $33 \cdot 2$ & 1.23 \\
\hline Germany & 883 & $32 \cdot 9$ & 1.05 \\
\hline Greece & 256 & $36 \cdot 4$ & 1.87 \\
\hline Iceland & 832 & $36 \cdot 5$ & 0.76 \\
\hline Ireland & 532 & $32 \cdot 0$ & $1 \cdot 36$ \\
\hline Italy & 607 & 33.7 & 1.70 \\
\hline Japan & 673 & $35 \cdot 9$ & $1 \cdot 10$ \\
\hline Luxemburg & 719 & $31 \cdot 3$ & $1 \cdot 11$ \\
\hline Netherlands & 851 & $34 \cdot 7$ & 1.07 \\
\hline New Zealand & 481 & $33 \cdot 1$ & 1.05 \\
\hline Norway & 822 & $34 \cdot 7$ & 0.96 \\
\hline Sweden & 1239 & $34 \cdot 9$ & 0.77 \\
\hline Switzerland & 990 & $35 \cdot 1$ & 0.91 \\
\hline United Kingdom & 539 & $32 \cdot 7$ & $1 \cdot 20$ \\
\hline United States & 1388 & $33 \cdot 3$ & $1 \cdot 26$ \\
\hline
\end{tabular}

* Source: OECD, 1985: Portugal, Spain, and Turkey are omitted because the data are incomplete.

tCalculated in current dollars by using purchasing power parity exchange rates.

\section{Setting an agenda}

ECONOMIC EVALUATION

Progress on deciding what to spend on health care cannot be made without more precise data on productivity. This requires economic evaluation in which the costs of interventions are related to their benefits

In the narrowest sense benefits can be measured in lives saved or life years saved, as in cost effectiveness analyses. In the widest sense these benefits can be measured in monetary units, as in cost-benefit analyses. Monetary estimates of benefits can be generated through willingness to pay techniques; but measures remain at present very experimental. ${ }^{3}$ A more limited improvement to the use of narrow measures is the quality adjusted life years (QALYs) approach. Limitations of QALYs should be recognised. ${ }^{56}$ They are but part of the ever improving field of outcome measurement.

In any case, with decent data on outcomes, within the health care budget, resources could be allocated to those areas where health gains to the community are greatest relative to expenditure, ensuring maximisation of the community's health given the resources available.

Economic evaluation can also be used to aid decision making regarding the size of the health care sector. Given a fixed level of funding for services, presumably a cut off point could be established above which services are funded (at the margin) and below which they are not. Those arguing for increased funding would then be able to present such results to governments and say that by not giving a specified number of pounds extra for health services, a specified number of units of health will be sacrificed. Claims about harm to the community from a lack of funding or the need for more efficiency in health services would be more easily substantiated or dismissed.

As has been pointed out, we have a duty to measure the effectiveness of health care in some form. If we do not have evidence that spending at a level of five times, three times, or twice a minimum level is beneficial is it surprising that cost cutting politicians choose the minimum level?
OTHER SECTORS' CONTRIBUTIONS TO HEALTH

Another point to bear in mind in endeavouring to determine where we go from here is that health care is but one factor through which health is improved or maintained. Would it be more productive in terms of health improvements to spend extra monies outside the health care system or within it? It may be that arguing for more health care resources is to the detriment of health if such resources are won at the expense of those resources being put into a more health productive area, such as education or housing. ${ }^{8-11}$

Once again the direction is one of searching for better measures of health outcome as well as evidence on the effects on health of not only health care but also investment in other health producing activities. It will then be possible to examine whether or not the greatest health improvements for the community will result from a larger or smaller budget for health care.

\section{Conclusions}

International comparisons of spending on health care are naive and unhelpful. There does not seem to be any point in refining a method of comparison that does not tell us what we want to know. The challenges for research and development are to continue devising measures of health gain and to increase the use of techniques of economic evaluation and analyses of determinants of health. This will not result in a uniform level of spending across countries but will help decide where increases and decreases in available resources are best targeted. If determining the size of the health care budget is not to be left in the hands of those providing unsubstantiated arguments in favour of expansion or cuts, the future for health care budget setting must, to a certain degree, rest with development of economic techniques.

\section{British Medical Association. Leading for health: a BMA agenda for health. London: BMA, 1991 \\ 2 Organisation for Economic Cooperation and Development. Measuring health care-1960-1983, expenditure, costs and performance. Paris: OECD, 1985. \\ 3 Donaldson C. Willingness to pay for publicly-provided goods: a possible measure of benefit? Fournal of Health Economics 1990;9:103-8. \\ 4 Williams A. Economics of coronary artery bypass grafting. BMJ 1985;291 $326-9$ \\ 5 Donaldson C, Atkinson A, Bond J, Wright K. Should QALYs be programme- specific. Fournal of Health Economics 1988;7:47-57. \\ 6 Loomes G, McKenzie L. The use of QALYs in health care decison making. Social Science and Medicine 1989;198:1336-43. \\ 7 Andersen TF, Mooney GH. The challenges of medical practice variations. Basingstoke: Macmillan Press, 1990. \\ 8 Carstairs V, Morris R. Deprivation: explaining differences in mortality between Scotland and England and Wales. BMF 1989;299:886-9. \\ 9 Grossman $M$. The correlation between health and schooling. In: Terleck NE, ed. Household production and consumption. New York: National Bureau of Economic Research, 1975 \\ 10 Corman H, Grossman M. Determinants of neonatal morbidity rates in the US: a reduced form model. Fournal of Health Economics 1985;4:213-36. \\ 11 Auster R. The production of health: an exploratory study. In Fuchs VR, ed. Essays in the economics of health and medical care. New York: Columbia University Press, 1985.}

(Accepled 13 February 1992)

\section{Correction}

\section{Laparoscopic or minilaparotomy cholecystectomy?}

An authors' error occurred in this article by J N Baxter and P J O'Dwyer (29 February, $p 559$ ). The final sentence of the first paragraph should have ended: "there is now accruing evidence of a poorer outcome including an increased mortality from the endoscopic procedure." 